\title{
Seroprevalence of Newcastle Disease Virus in Local Chickens in Njombe and Bahi Districs in Tanzania
}

\section{Elifuraha Barnabas Mngumi ( $\nabla$ emngumi@yahoo.com )}

Sokoine University of Agriculture https://orcid.org/0000-0003-3815-1966

\section{Emmanuel Bunuma}

Tanzania Vaccine Institute-TVLA

\section{Research Article}

Keywords: NCD, NDV, Avulavirus, Seroprevalence, Poultry, Tanzania.

Posted Date: August 30th, 2021

DOI: https://doi.org/10.21203/rs.3.rs-712858/v1

License: (9) This work is licensed under a Creative Commons Attribution 4.0 International License. Read Full License 


\section{Abstract}

Newcastle disease virus (NDV) causes significant losses of poultry in Tanzania. Like in many African countries, the regular surveillance of NDV is important for the control of disease. The objective of this study was to determine seroprevalence of NDV in backyard poultry in Bahi and Njombe districts of Tanzania over the rainy (May) and dry (November) seasons in 2016. Using hemaglutination inhibition test, the overall seroprevalence was determined to be $26.8 \%$. The significant differences in seroprevalence was between seasons ((higher $(34.9 \%)$ in dry season, $p<0.0001)$ ) and age ((higher $(30.3 \%), p<0.0001$ in adult birds)). There were no significant differences in seroprevalence between the districts or sex. The higher levels of "protective" antibody titers were significantly associated with location; Njombe (RR 1.15), dry season (RR 1.08), and age; adult birds (RR 1.16), however the prevalence of these titers was not high enough to conclude any herd immunity among these flocks. This study therefore provides a brief insight of NDV disease dynamics in Tanzania. Future studies focusing on transmission, strain type, and monthly dynamics of NDV in backyard flocks will provide greater insight into the disease dynamics and allow new practical strategies to alleviate the effects of NDV for the smallholder farmers

\section{Introduction}

Newcastle disease virus (NDV) causes a devastating disease in poultry, especially in developing countries due to the constant threat of infection from lack of proper vaccination strategies and scavenging environments(Alexander, 2000; Ananth et al., 2008). With the greatest impacts of NDV occurring in backyard poultry due to high mortality rates in susceptible flocks, the pathogen poses significant threats to small-holder farmers whose livelihoods depend on the productivity of their flocks for both egg and meat production (Alexander, 2000; Ananth et al., 2008; Alexander et al., 2012).

Many countries in both Africa and Asia have reported endemic NDV, including Kenya, Ethiopia, Nigeria, Sudan, Uganda, Tanzania (Awan et al., 1994; Lawal et al., 2016). Although these countries have reported positive serology, there is no indication of whether the backyard chickens were exposed to lentogenic (low pathogenic), mesogenic (moderate pathogenic), or velogenic (highly pathogenic) strains of the virus, which is particularly important due to all three types of strains previously being isolated from Tanzanian backyard poultry (Awan et al., 1994; Yongolo et al., 2011). It is important to understand the overall prevalence of NDV as well as the pathogenicity of these field isolates in order to understand the impacts of infection in these countries.

In Tanzania, like most other African countries, there is a large population of backyard poultry with over $90 \%$ of all poultry being farmed extensively (Ministry of Agruculture et al., 2016). In these conditions, the chickens are regularly exposed to inadequate feeds, poor management and housing, predation, and infectious diseases (Minga et al., 2004; Gilbert et al., 2015; Lawal et al., 2016; Muchadeyi and Dozmba, 2017). There are also risk factors in these farms that contribute to the spread and persistence of infection including the absence of preventative measures or vaccination, frequent contact with wild birds, improper disposal of carcasses and waste products, and the general practice of selling/buying birds which all have 
the possibility of introducing disease to healthy birds and flocks (Chaka et al., 2013). Other factors also contribute to infection in the chickens, such as age, immune status, season, breed, and other environmental factors (Awan et al., 1994).

This study in Tanzania was implemented to provide a better understanding of the seroprevalence of NDV in backyard poultry and to assess risk factors associated with the disease. The information may be useful in devising new improved strategies for the control and prevention of ND in smallholder farmers.

\section{Material And Methods}

\section{Study area}

The study was conducted in Njombe and Bahi districts in Tanzania (Figure 1). Njombe district is found inNjombe region in the southern highlands of Tanzania and is roughly 2000 meters above sea level.It is located atlatitude $9^{\circ} 20.069^{\prime} \mathrm{S}$ and longitude $34^{\circ} 45.912^{\prime} \mathrm{E}$. The annual temperature ranges from 10.6$22.1^{\circ} \mathrm{C}$, with an average of $16.4^{\circ} \mathrm{C}$. The annual average precipitation is $1140 \mathrm{~mm}$ whereas Bahi is found in the Dodoma region of the central zone of Tanzania and is characterized by semi-arid conditions. It is located $841 \mathrm{~m}$ above the sea level at latitude $5^{\circ} 56.973^{\prime} \mathrm{S}$ and longitude $35^{\circ} 18.785^{\prime} \mathrm{E}$. The annual temperature ranges from $16-29^{\circ} \mathrm{C}$, with an average of $22.7^{\circ} \mathrm{C}$. The annual average precipitation is $579 \mathrm{~mm}$.

\section{Study design}

Local chickens in the Bahi and Dodoma districts of Tanzania were sampled during both rainy (end of May) and dry (end of November) seasons in 2016 (Figure 1). A repeated cross sectional study was conducted in May and November in 2016, the months that represented end of rainy season and dry season respectively. A total of 803 blood samples (425 from Bahi -230 dry and 195 rainy; 378 from Njombe - 228 dry and 150 rainy) from apparently healthy local chickens were collected. Metadata of the collected samples can be found in Supplemental Table 1.

\section{Ethical issues and consent to participate}

The research was approved by the institutional committee for research and innovation at the Nelson Mandela African Institution of Science and Technology (NM-AIST). The sampling and handling of chickens was performed by a licensed veterinarian. Permission to conduct the research was approved by the Government leaders at the district and village levels. Recruitments of farmers to the study were done after informed consents were provided by farmers themselves, either by the household head or alternative responsible person.

\section{Blood collection from chickens and Hemagglutinationinhibition test}

Approximately $2 \mathrm{ml}$ of blood was collected aseptically from the wing vein in a disposable syringe and stored at room temperature for six hours. Serum was gently separated and stored via eppendorf vials in a 
cooler box with ice blocks until arrival at the laboratory where they were stored at $-20^{\circ} \mathrm{C}$.

Hemagglutination inhibition (HI) tests were performed according to protocols described by OIE (2012). Briefly, $1 \%$ chicken red blood cells (RBC) were prepared from apparently healthy, unvaccinated 8 weeks old layer chickens. The viral antigen was from an I-2 attenuated vaccine obtained from Tanzania Veterinary Laboratory Agency (TVLA) using embryonated chicken eggs as previously described (OIE), 2012). $\mathrm{HI}$ tests were performed by first dispensing $25 \mu \mathrm{l}$ of phosphate buffered saline (PBS) into wells of a plastic V-bottomed 96 -well microtiter plate. Then $25 \mu$ l of test sera were added into the first row of wells followed by serial dilutions by transferring $25 \mu$ l of the content to consecutive wells until the 10 th column. This was followed by adding a $25 \mu$ l of previously prepared $4 \mathrm{HA}$ antigen up to 11 th column. The plate was left to stand for about 30 minutes at ambient temperature. The $11^{\text {th }}$ and $12^{\text {th }}$ wells were considered control wells and for checking non-specific agglutinins respectively. In each test, previously prepared positive and negative control sera were included in the test. A $25 \mu$ l of $1 \%$ chicken RBCs was added to each well and, after gentle mixing, the plate was left for about 40 minutes at room temperature to allow settling of RBC. The agglutination inhibition was assessed by tilting the plates to observe RBC stream in reference to controls.

\section{Data analysis}

The counts for seropositive chickens were computed to determine the prevalence of seroposivity and for the prevalence "protective" antibodies. Positive antibodies were considered as titers greater than 4 and "protective" were considered as titers greater than 8 (Kemboi et al., 2013). The overall prevalence (positive samples) and "protective" antibodies (titers greater than 8) were compared between region, season, age, and sex. These samples were also stratified by region and compared between season, age, and sex. The antibody titers were $\log _{2}$ transformed for descriptive and t-test analysis using R. Risk ratios were calculated using the epitools package in $\mathrm{R}$.

\section{Results}

\section{Prevalence of NDV seropositivity}

Table 1 shows the overall prevalence of NDV antibodies and prevalence stratified by season, age and sex. The overall prevalence of NDV in the backyard chickens of Tanzania is $26.8 \%$. There were significant differences between titers in rainy versus dry season $(15.9 \%$ and $34.9 \%$, respectively; $p$-value $<0.0001)$ and between adult and non-adult birds $(30.3 \%$ and $12.4 \%$, respectively; $p$-value $<0.0001)$. However, there were no significant differences between the regions and sex of the birds $(28.7 \%$ and $24.6 \% ; 26.7 \%$ and $26.9 \%$, respectively). Within each region there was a significant difference in the titers between seasons, and in Njombe the titers between the adult and non-adult birds were significant as well.

Violin plots representing the distribution of $\mathrm{HI}$ titers show a much larger count of negative samples than positive samples across all strata (Figure 2). Comparing strata with no significant differences between the samples tends to show similar distribution patterns, for example the distribution of antibody titers 
between male and female chickens is almost equal (Figure 2D and 2G). Comparing those strata with significant differences, the distribution patterns have many differences. For example in Figure $2 \mathrm{C}$ ( $\mathrm{p}$-value $<0.0001$ ), there is a much larger distribution of negative samples in the non-adult and the distribution is skewed more toward high positives in the adults. This is true for the samples stratified by season as well ( $p$-value $<0.0001$ ), with a much larger distribution of positive titers in dry than during the rainy season, although the overall titers are higher in rainy season.

Table 1: Prevalence of seropositivity and protective antibodies stratified by regions, season, age and sex 
Positive Negative Total (Protective)

Sero-

prevalence

(Protective)

All Data

\begin{tabular}{|c|c|c|c|c|c|c|c|}
\hline $\begin{array}{l}\text { Overall } \\
\text { Prevalence }\end{array}$ & $\begin{array}{l}215 \\
(104)\end{array}$ & 588 & 803 & $\begin{array}{l}26.8 \\
(13.0)\end{array}$ & & & \\
\hline \multirow[t]{2}{*}{ Region } & Bahi & $122(31)$ & 303 & 425 & $28.7(7.3)$ & $(24.4,33.3)$ & 0.19 \\
\hline & Njombe & $93(73)$ & 285 & 378 & $24.6(19.3)$ & $(20.3,29.3)$ & \\
\hline \multirow[t]{2}{*}{ Season } & Rainy & $55(32)$ & 290 & 345 & $15.9(9.3)$ & $(12.2,20.2)$ & $<0.0001$ \\
\hline & Dry & $160(72)$ & 298 & 458 & 34.9 (15.7) & $(30.6,39.5)$ & \\
\hline \multirow[t]{2}{*}{ Age } & Adult & $191(100)$ & 439 & 630 & $30.3(15.9)$ & $(26.7,34.1)$ & $<0.0001$ \\
\hline & $\begin{array}{l}\text { Non- } \\
\text { Adult }\end{array}$ & $24(4)$ & 149 & 170 & $12.4(2.4)$ & $(7.8,18.3)$ & \\
\hline \multirow[t]{2}{*}{ Sex } & Female & $156(78)$ & 429 & 585 & 26.7 (13.3) & $(23.1,30.4)$ & 0.96 \\
\hline & Male & $58(25)$ & 158 & 216 & $26.9(11.6)$ & $(21.1,33.3)$ & \\
\hline
\end{tabular}

\section{By Region}

\begin{tabular}{|c|c|c|c|c|c|c|c|}
\hline \multirow[t]{6}{*}{ Bahi } & Rainy & $30(11)$ & 165 & 195 & $15.4(5.6)$ & $(10.6,21.2)$ & $<0.0001$ \\
\hline & Dry & $92(20)$ & 138 & 230 & $40.0(8.7)$ & $(33.6,46.6)$ & \\
\hline & Adult & $101(29)$ & 233 & 334 & $30.2(8.7)$ & $(25.4,35.5)$ & \multirow[t]{2}{*}{0.23} \\
\hline & $\begin{array}{l}\text { Non- } \\
\text { Adult }\end{array}$ & $21(2)$ & 70 & 91 & $23.1(2.2)$ & $(14.9,33.1)$ & \\
\hline & Female & $80(21)$ & 215 & 295 & $27.1(7.1)$ & $(22.1,32.6)$ & \multirow[t]{2}{*}{0.36} \\
\hline & Male & $41(9)$ & 87 & 128 & $32.0(7.0)$ & $(24.1,40.9)$ & \\
\hline \multirow[t]{6}{*}{ Njombe } & Rainy & $25(21)$ & 125 & 150 & $16.7(14.0)$ & $(11.1,23.6)$ & 0.005 \\
\hline & Dry & $68(52)$ & 160 & 228 & $29.8(22.8)$ & $(24.0,36.2)$ & \\
\hline & Adult & $90(71)$ & 206 & 296 & $30.4(24.0)$ & $(25.2,36.0)$ & \multirow[t]{2}{*}{$<0.0001$} \\
\hline & $\begin{array}{l}\text { Non- } \\
\text { Adult }\end{array}$ & $3(2)$ & 79 & 82 & $3.7(2.4)$ & $(0.8,10.3)$ & \\
\hline & Female & $76(57)$ & 214 & 290 & $26.2(19.7)$ & $(21.2,31.7)$ & \multirow[t]{2}{*}{0.24} \\
\hline & Male & $17(16)$ & 71 & 88 & $19.3(18.2)$ & $(11.7,29.1)$ & \\
\hline
\end{tabular}


The patterns of higher positive titers become more apparent in Figure 3 when examining only the "protective" antibody titers. The overall prevalence of "protective" levels of antibody is $13 \%$. All strata seem to show the higher the titer the fewer amounts of chickens, demonstrating although the titer is considered "protective", the titer is still not high. Comparing the amount of "protective" antibody titers present between seasons and age exhibited a significance difference; however there was no significant difference between region and sex. When stratifying the data by region first, the sample sizes become small, and although there are significant differences between adult and non-adult chickens in both Bahi and Njombe (p-values 0.04 and 0.007 , respectively), the sample size of non-adult birds in each group is equal to 2, so larger samples sizes of non-adult birds is needed to confirm these results.

\section{Risk Ratios, "protective antibody" characteristics}

Factors contributing to the likelihood of having a "protective" antibody titer among local chickens determined through risk ratios with a calculated 95\% confidence interval (Figure 4). Examining regionally, chickens are more likely to have a "protective" level of antibody titers in the Njombe (RR 1.15, 95\% Cl 1.091.22) district versus Bahi district ( $\mathrm{RR} 0.87,95 \% \mathrm{Cl} 0.82-0.92$ ) (Figure 4, green dots). There is a slightly higher chance of having protection in the dry season (RR $1.08,95 \% \mathrm{Cl} 1.02-1.13)$ versus the rainy season (RR $0.93,95 \% \mathrm{Cl} 0.88-0.98$ ) as well (Figure 4, blue dots). There is also a significant likelihood of protection in adults (RR 1.16, 95\% Cl 1.11-1.21)compared to non-adult chickens ( $R R 0.83,95 \% \mathrm{Cl} 0.83-0.89$ ) (Figure 4, red dots). However, there is no greater chance between males and females in having "protective" HI titers (Figure 4, purple dots). The respective risk ratio were $0.98,95 \% \mathrm{Cl} 0.93-1.04$ and $1.02,95 \% \mathrm{Cl} 0.96-1.08$ ).

\section{Discussion}

Preceding studies have determined the prevalence of NDV in Tanzania to be 37.2-46.8\%, respectively (Yongolo, 1996; Yongolo et al., 2002).This study estimated seroprevalence to be somewhat lower, around $26 \%$. The lower seroprevalence could be accounted to seasonality while previous studies examined their prevalence throughout a 12-month period in 1995 and had peak prevalence occurring in October this specific study the sampling was done in May and November. Nevertheless, there is consistent with our findings demonstrating higher seroprevalence at the end of dry season, November, than rainy season, May. This study also demonstrates overall trends of significantly higher seroprevalence in adult versus non-adult backyard chickens (Table 1). These results are consistent with studies done in Kenya and Ethiopia that found higher seroprevalence in adult birds and during dry season. Also, the present study showed no significance difference between male and female, the findings which differ from that reported by Nwanta et al.(2008), Kemboi et al. (2013) and Geresu et al. (2016) where higher seroprevalence was in female versus male chickens ( $p$-value $=0.96)$.

The overall, higher seroprevalence to NDV in dry season could be contributed to increased nutritional stress during dry versus rainy season. When there is less rain and drought conditions, water and food sources, such as insects and greens, become scarce for the scavenging chickens which leads to increased stress in additional to environmental stress such as higher temperatures during these times 
(Msami, 2002). Susceptibility to disease has been linked to nutritional deficiencies, such as Vitamin A and iron, which are especially critical to the proper development of the immune system in chickens (Klasing, 1998). Studies have also reported that Vitamin A supplements reduce NDV mortality by $36 \%$ in some instances (Opke et al., 2015). Due to the poorer nutritional status of chickens during dry season, this could be a major contributing factor to higher infection rates and possibly higher seroprevalence during dry season as compared to rainy season as demonstrated by our data. Interestingly, although results data analysis demonstrates higher seroprevalence and rate of protection in dry season, there are significantly higher overall and "protective" antibody titers in the rainy season (Fig. 2 and Fig. 3). This higher overall titer could be contributed to the few outliers in the rainy season group (Fig. 2) that skew the data and drive the significance of higher titers in rainy season than dry season; however, this remains an area of interest for future studies to examine the seasonality and transmission dynamics of NDV infection in Tanzania.

The overall lower seroprevalence in non-adult chickens could be related to the shorter period of exposure of chicks to NDV compared to adults (McFerran and McCracken, 1988). This may also suggest that higher seroprevalence in adult means birds were exposed to NDV, possibly as chicks and then survived to adulthood.

These findings also demonstrate that there is a greater chance of having a "protective" level of antibody titer if the chicken is from Njombe, during dry season, or is an adult, however, the chance of having "protective" antibody titers overall is low (Fig. 5). Although these "protective" levels of titers are present in the backyard chicken population, the prevalence is not high enough to infer any type of herd immunity to NDV. One definition of herd immunity relates high numbers of immune individuals reducing the transmission of disease to others and ultimately eradicating the disease (John and Samuel, 2000). The low prevalence of "protection" among the backyard chickens in Tanzania demonstrates the need for future strategies to help smallholder farmers prevent disease in their flocks.

This data begins to provide insight on the disease dynamics of NDV in Tanzania, although many unanswered questions still remain. It is apparent that these chickens are exposed to NDV in the field, and even produce high antibody titers, yet remain alive and healthy. Another area to be investigated and understood in greater detail is the underlying mechanisms contributing to the survival of the chickens in the face of NDV exposure. Future studies focusing on transmission, strain type, and monthly dynamics of NDV in backyard flocks will also provide greater insight into the disease dynamics and allow future implementation of strategies to alleviate the effects of NDV for the smallholder farmers of Sub-Saharan Africa to maximize productivity of their flocks as a source of food and contribute to the overall health of their families and communities.

\section{Declarations}

Not applicable.

\section{Data sharing}


All data are included in this article and Supplemental Table S1

\section{Conflict of interest statement}

There is no conflict of interest.

\section{Author's contribution}

EM and EB designed the study, collected samples and laboratory testing. EM did data analysis and wrote the manuscript. EB revised the content. Both authors read and approved the final manuscript.

\section{Funding}

No external fund was used to design and publish this work

\section{Acknowledgements}

First and foremost we wish to extend our sincere appreciation to Dr. Ziwa Michael, Veterinary Officer-Bahi district and Dr. Anthony Mwangolombe, Veterinary Officer-Njombe district, for their immense support in planning for sampling in their respective districts. The ward livestock officers made our sampling activities possible. Next in the list are Mr. Jonas Fitwangile and Rugaimukamu, E.A., the technicians at the Department of Veterinary Microbiology and Parasitology, Sokoine University of Agriculture for the technical support in carrying out the laboratory tests. We also thank very much poultry farmers in Njombe and Bahi districts for their good will to provide chickens for sample collection. Without them the work could not have been a success.

\section{References}

1. Alexander, D.J. 2000. Newcastle disease and other Avian paramyxoviruses. Revue scientifique et technique, $19,443-462$.

2. Alexander, D.J., Aldous, E.W. and Fuller C.M. 2012. The long review: a selective review of 40 years of Newcastle disease research. Avian Pathology, 41(4), 329-335.

3. Ananth, R., Kirubaharan, J.J., Priyadarshini, M.L. M. and Albert, A. 2008. Isolation of Newcastle disease viruses of high virulence in unvaccinated healthy village chickens in South India. International Journal of Poultry Science, 7 (4), 368-373.

4. Awan, M.A., Otte, M.J. and James, A.D. 1994. The epidemiology of Newcastle disease in rural poultry: a review. Avian Pathology, (23), 405-423.

5. Chaka, H., Goutard, F., Roger, F., Bisschop, S.P.R., and Thompson, P.N. 2013. Household-level risk factors for Newcastle disease seropositivity and incidence of Newcastle disease virus exposure in backyard chicken flocks in Eastern Shewa zone, Ethiopia. Preventive Veterinary Medicine, 109. (2013) 312-320. 
6. Geresu, M.A., Elemo, K.K. and Kassa, G.M. 2016. Newcastle disease: Seroprevalence and associated risk factors in backyard and small scale chicken producer farms in Agarfa and Sinana districts of Bale Zone, Ethiopia. Journal of Veterinary Medicine and Animal Health, 8, 99-106. https://doi.org/10.5897/JVMAH2015.0427.

7. Gilbert, M., Conchedda, G., Boeckel, T., Cinardi, G., Linard, C., Nicolas, G., Thanapongtharm, W., D'Aietti, L.,Wint, W.,Newman, S.H., and Robinson, T.P.. 2015. Income disparities and the global distribution of intensively farmed chickens and pigs. PLoS ONE, 10 (7) e0133381. https://doi.org/10.1371/journal.pone.0133381

8. John, T.J., and Samuel, R. 2000. Herd immunity and herd effect: New insights and definitions. European Journal of Epidemiology, 16, 601-606

9. Kemboi, D.C., Chegeh, H.W., Bebora, L.C., Maingi, N., Nyaga, P.N., Mbuthia, P.G., et al. 2013. Seasonal Newcastle disease antibody titer dynamics in village chickens of Mbeere District, Eastern Province, Kenya. Livestock Research for Rural Development, 25(10).

10. Klasing, K.C. (1998). Nutritional modulation of resistance to infectious diseases. Poultry Science, 77 (8), 1, 1119-1125

11. Lawal, J., El-Yuguda, A., and Ibrahim, U. 2016. Survey on Prevalence of Newcastle Disease Antibodies in Village Poultry at Live Birds Markets in Gombe, Nigeria. Journal of Animal Science and Livestock Production, 1(1).

12. McFerran, J.B., and McCracken, R.M. 1988. Newcastle Disease. Norwell, MA: Kluwer Academic Publishers.

13. Minga, U., Msoffe, P., and Gwakisa, P. 2004. Biodiversity (variation) in disease resistance in pathogens within rural chicken populations. Microsoft Word - 614.doc (psu.edu).

14. Nationa Bureau of Statistics (NBS) (2016). "2014/15 Annual Agricultural Sample Survey Report", in: The United Republic of Tanzania.). Annual_Agricultural_Sample_Survey_Report2014_15.pdf (nbs.go.tz)

15. Msami, H.M. 2002. "Studies on the structure and problems of family poultry production in Tanzania", in: Proceedings of the Research coordination meeting of IAEA).

16. Muchadeyi, M., and Dozmba, E. 2017. Genomics Tools for the characterization of genetic adaptation of low Input Extensively Raised Chickens. In: Milad Manafi (Eds.), Poultry Science https://doi.org/10.5772/65679

17. Nwanta, J.A., Egege, S.C., Alli-Balogun,J.K. and Ezema, W.S. 2008. Evaluation of prevalence and seasonality of Newcastle disease in chicken in Kaduna, Nigeria. World's Poultry Science Journal, 64 (03), 416-423.

18. OIE Terestrial mannual. 2012. Manual of Diagnostic Tests and Vaccines for Terrestrial Animals.

19. Opke, G.C., Ezma, W.S., Shoyinka, S.V.O., and Okoye, J.O.A. 2015. Vitamin A dietary supplementation reduces the mortality of velogenic Newcastle diease significantly in cockerels. International Journal of Experimental Pathology 96. doi: 10.111/iep.12138. 
20. Yongolo, M. 1996. Epidemiology of Newcastle disease in village chickens in Tanzania. Master's of Science, Sokoine University of Agriculture.

21. Yongolo, M.G., Christensen, H., Handberg, K., Minga, U. and Olse, J.E. 2011. On the origin and diversity of Newcastle disease virus in Tanzania. Onderstepoort Journal of Veterinary Research 78(1), art No. 312:8p.

22. Yongolo, M.G.S., Machangu, A.M. and Minga, U.M. 2002. Newcastle disease and Infectious bursal disease among free range village chickens in Tanzania. In: IAEA, Characteristics and parameters of family poultry production in Africa, Vienna, 107-116. http://www-naweb.iaea.org/ nafa/aph/public/aph-poultry-africa.htm.

\section{Figures}

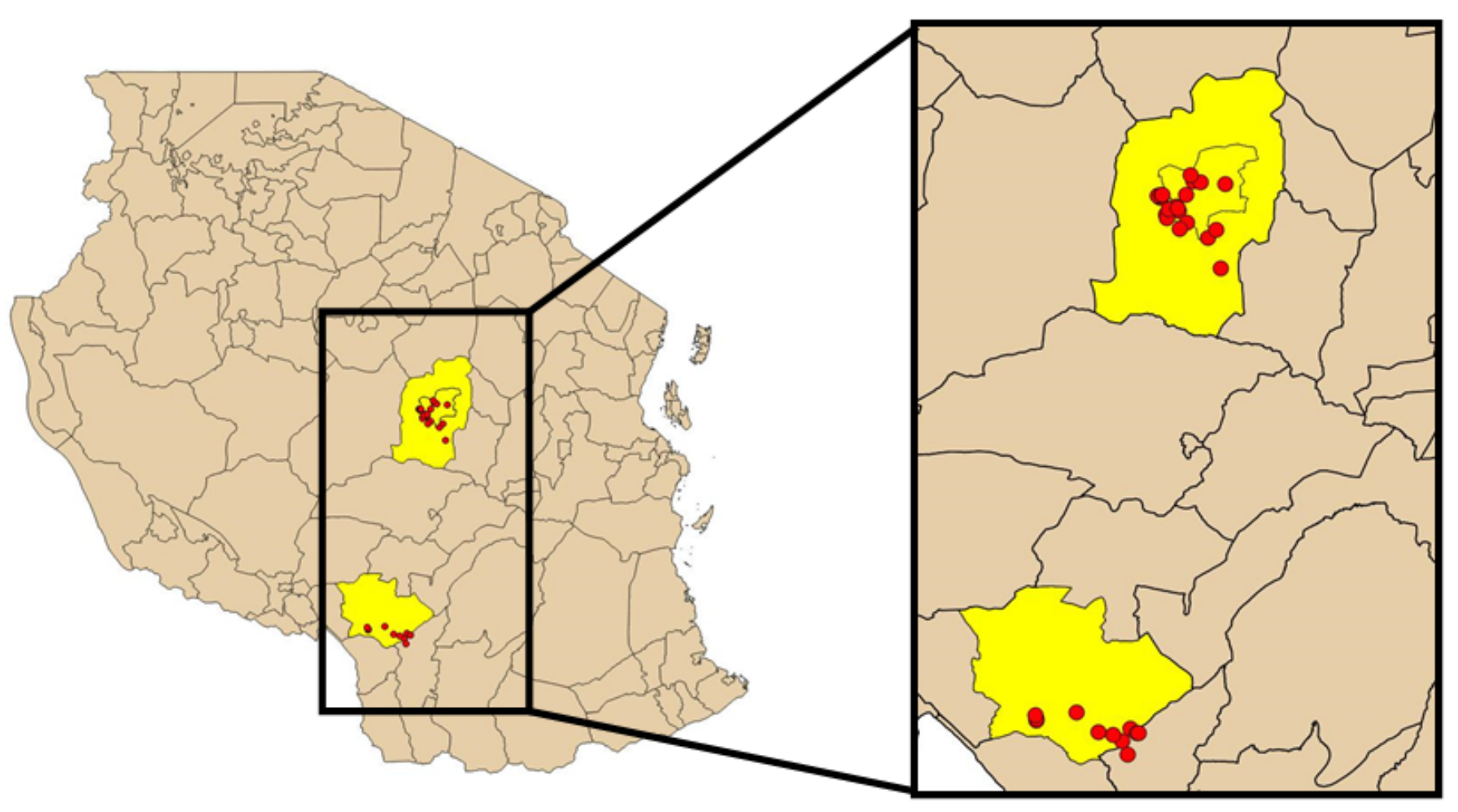

Figure 1

Map of the distribution of sampling. The two districts, Dodoma (top) and Njombe (bottom), are highlighted in yellow. The red dots represent individual farms where sampling occurred 

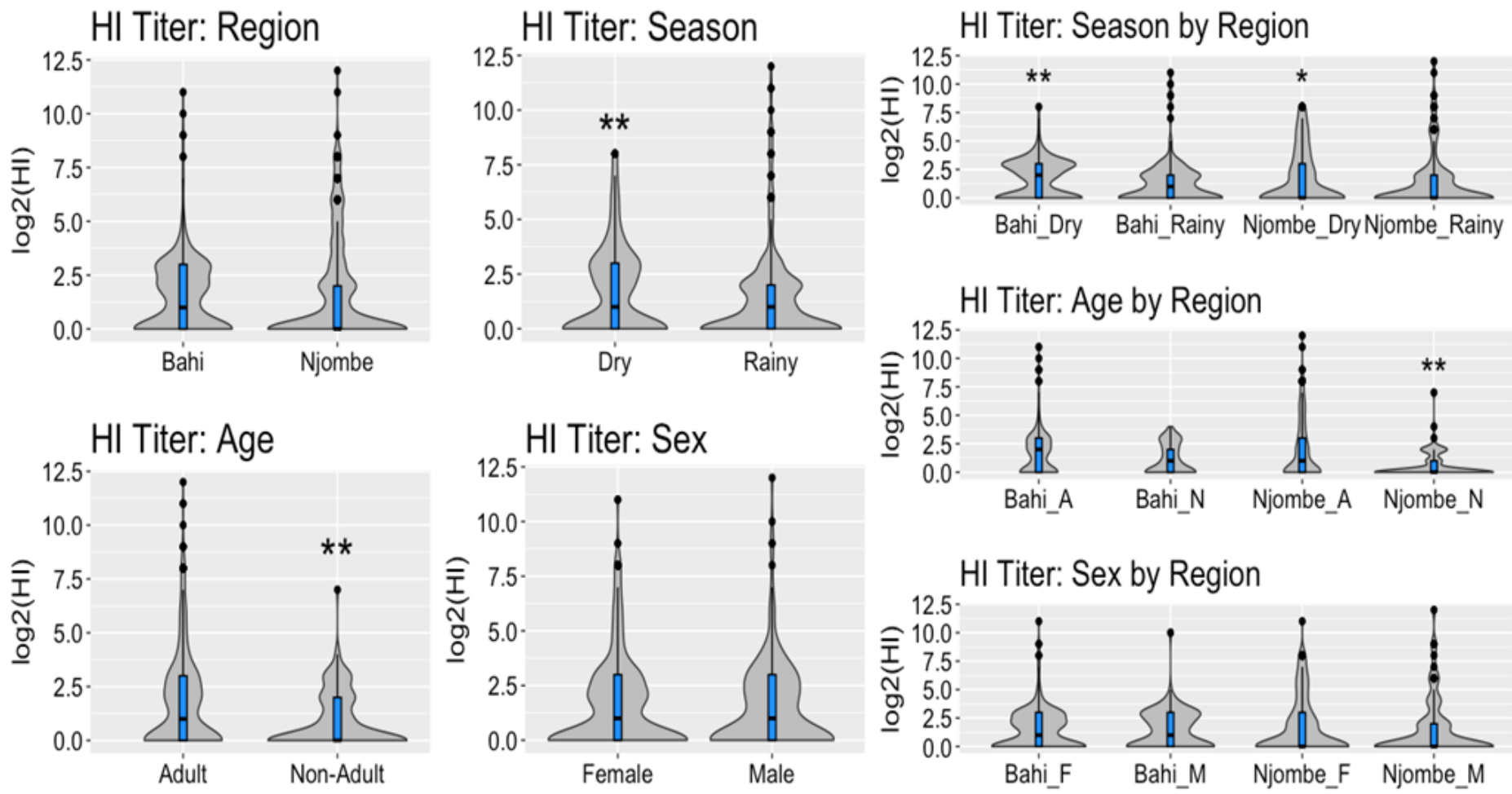

Figure 2

Overall $\mathrm{HI}$ titers for all samples. The log2(HI) titers for both positive and negative samples were included in these figures. Samples are stratified A) regionally, B) seasonally, C) by age, and D) by sex. The samples were also stratified by region then by E) season, F) age, and G) sex. The blue represents the boxplot and the grey represents the violin plot of the distribution of the titers. (*p-value $<0.001$, ${ }^{\star \star} p$-value $<0.0001$ ). 
HI Titer: Region
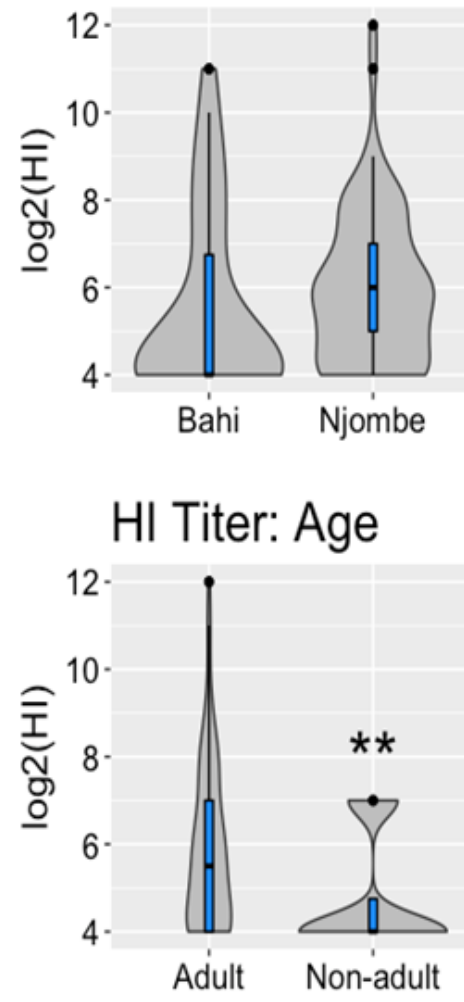

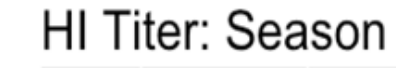

12 -
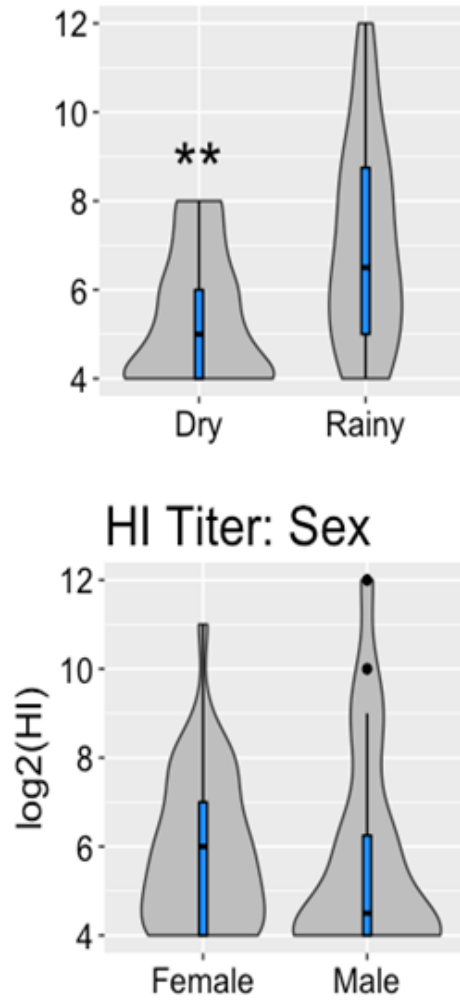

HI Titer: Season by Region

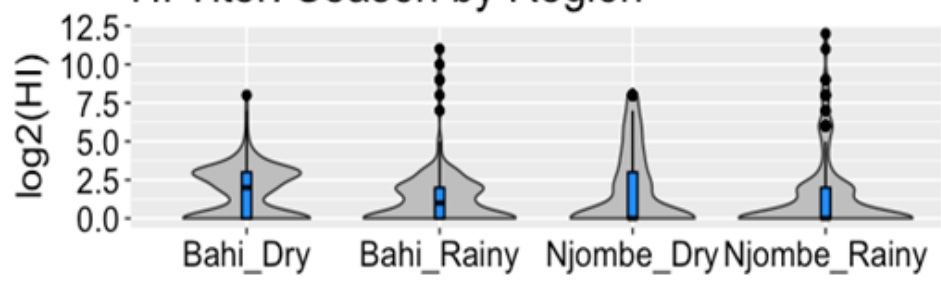

HI Titer: Age by Region

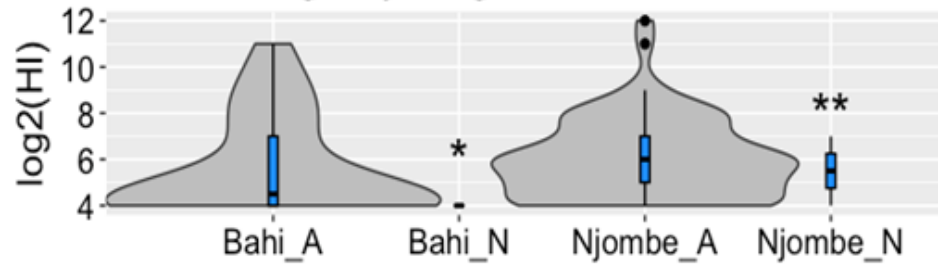

HI Titer: Sex by Region

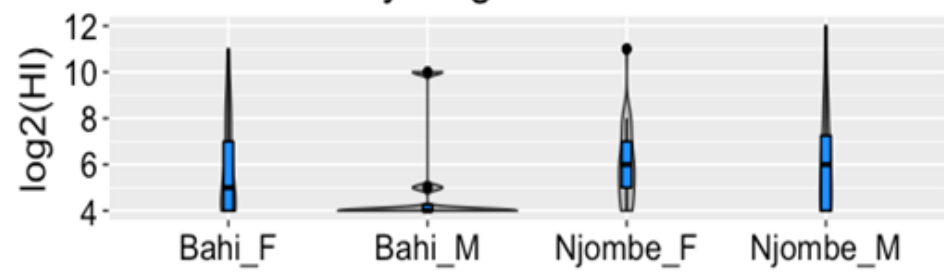

Figure 3

"protective" HI Titers. The log2 ( $\mathrm{HI})$ greater than 3, equating to "protective" levels of antibody titers, are represented in this figure. Samples are stratified A) regionally, B) seasonally, C) by age, and D) by sex. The samples were also stratified by region then by $E$ ) season, F) age, and G) sex. The blue represents the boxplot and the grey represents the violin plot of the distribution of the titers. ( ${ }^{*} p$-value $<0.05,{ }^{*} p$-value $<$ 0.01). 


\section{Risk Ratio $(95 \% \mathrm{Cl})$}

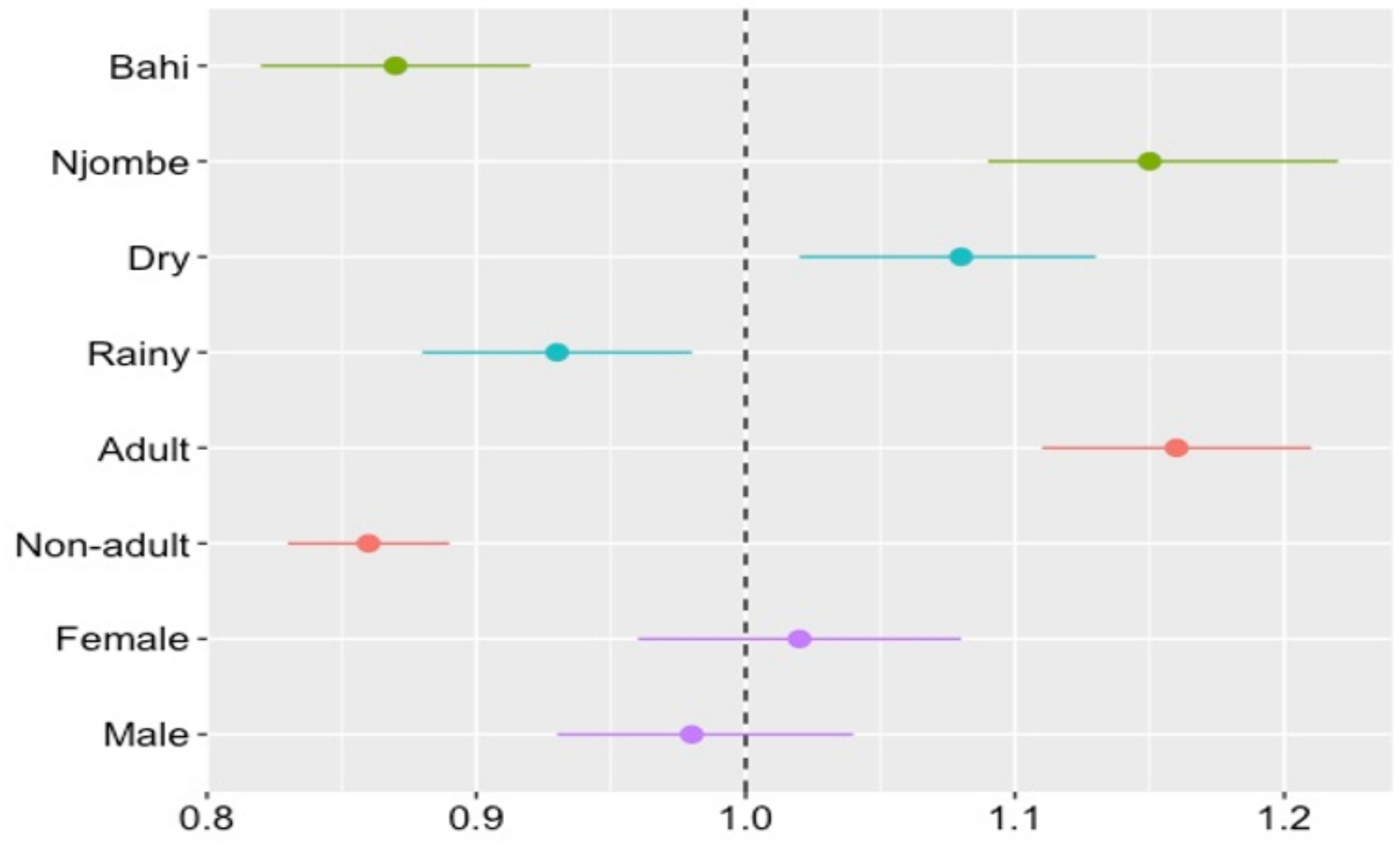

\section{Figure 4}

Risk Ratios of having "protective" antibody titers. Represented in this figure is the relative risk (dots) of having versus not having "protective" levels of antibody titers and the $95 \%$ confidence interval (lines). The green color represents the regions, blue represents seasons, red represents age, and purple represents sex.

\section{Supplementary Files}

This is a list of supplementary files associated with this preprint. Click to download.

- SupplimentalTableS1.csv 